\title{
Dietary patterns associated with fall-related fracture in elderly Japanese: a population based prospective study
}

\author{
Yasutake Monma ${ }^{\dagger 1}$, Kaijun Niu², Koh Iwasaki*3, Naoki Tomita4, Naoki Nakaya5, Atsushi Hozawa ${ }^{5}$, Shinichi Kuriyama5, \\ Shin Takayama³, Takashi Seki³, Takashi Takeda³, Nobuo Yaegashi1,3, Satoru Ebihara6 ${ }^{6}$, Hiroyuki Arai ${ }^{4}$ Ryoichi Nagatomi² \\ and Ichiro Tsuji 5
}

\begin{abstract}
Background: Diet is considered an important factor for bone health, but is composed of a wide variety of foods containing complex combinations of nutrients. Therefore we investigated the relationship between dietary patterns and fall-related fractures in the elderly.

Methods: We designed a population-based prospective survey of 1178 elderly people in Japan in 2002. Dietary intake was assessed with a 75-item food frequency questionnaire (FFQ), from which dietary patterns were created by factor analysis from 27 food groups. The frequency of fall-related fracture was investigated based on insurance claim records from 2002 until 2006. The relationship between the incidence of fall-related fracture and modifiable factors, including dietary patterns, were examined. The Cox proportional hazards regression model was used to examine the relationships between dietary patterns and incidence of fall-related fracture with adjustment for age, gender, Body Mass Index (BMI) and energy intake.
\end{abstract}

Results: Among 877 participants who agreed to a 4 year follow-up, 28 suffered from a fall-related fracture. Three dietary patterns were identified: mainly vegetable, mainly meat and mainly traditional Japanese. The moderately confirmed (see statistical methods) groups with a Meat pattern showed a reduced risk of fall-related fracture (Hazard ratio $=0.36,95 \% \mathrm{Cl}=0.13-0.94$ ) after adjustment for age, gender, BMl and energy intake. The Vegetable pattern showed a significant risk increase (Hazard ratio $=2.67,95 \% \mathrm{Cl}=1.03-6.90$ ) after adjustment for age, gender and BMI. The Traditional Japanese pattern had no relationship to the risk of fall-related fracture.

Conclusions: The results of this study have the potential to reduce fall-related fracture risk in elderly Japanese. The results should be interpreted in light of the overall low meat intake of the Japanese population.

\section{Background}

Fracture accidents in the elderly reduces their activity of daily life [1] and also increases mortality [2-4]. Diet is considered an important factor for the maintenance of bone health [5-7]. Many nutrients, not only calcium [8,9] and Vitamin D [10], but also phosphorus, vitamin K, strontium and magnesium [11,12], contribute to bone health Bone is a complex living tissue, however, and a

\footnotetext{
*Correspondence: QFG03604@nifty.com

3 Center for Asian Traditional Medicine, Tohoku University Graduate School of Medicine

+ Contributed equally

Full list of author information is available at the end of the article
}

wide spectrum of micronutrients also contribute to its maintenance. Moreover, diets are composed of a wide variety of foods containing complex combinations of nutrients. Therefore, surveys that examine a single nutrient in foods may not adequately account for complicated interactions and cumulative effects on human health.

Tucker et al. [13] and Okubo et al. [14] categorized diets into dietary patterns in order to clarify the relationship between diet and bone mineral density (BMD). Tucker and colleagues reported that a diet with a high fruit and vegetable content appears to have a protective effect on BMD in males while high candy consumption may be associated with low BMD. Okubo et al. demon- 
strated the possibility that a dietary pattern with high intakes of fish, fruit, and vegetables and a low intake of meats may have a beneficial effect on BMD. Tucker and Okubo's observation, however, was not extended to look for associations between dietary patterns and fractures. There is no report investigating the relation of dietary patterns and fall-related fracture. Furthermore, the population studied by Okubo et al. was made up of pre-menopausal women. Though Tucker et al. studied an elderly population, the dietary habits of people from Western versus Asian countries are entirely different. As is well known, Japanese food is characterized by rice and soy bean products, and contains many types of fish, seafood and vegetables but only small amounts of meat or dairy products [15]. Therefore, in the present study, we examined the relationship between dietary patterns and fractures in elderly Japanese living in a suburb of Sendai, one of the largest cities in Northern Japan.

\section{Methods \\ Study population}

Our study population consisted of elderly subjects living in the Tsurugaya area of Sendai, the largest city of Tohoku (North-eastern) district in Japan. At the time of the study in 2002, there were 2730 people aged over 70 years living in the area. We invited all of these people to participate in a comprehensive geriatric assessment of medical status of whom 1178 agreed to participate and provided written informed consent for a baseline assessment. Of these 1178, we excluded 213 subjects who did not agree to the follow up survey, 77 with incomplete dietary data and 11 whose cognitive level was lower than 18 in the Mini Mental State Examination (MMSE) score [16]. Therefore, 877 participants whose medical status, activities of daily living (ADL), and life style, including dietary intakes, were assessed in July 2002 were followed up for their incidence of fall related fracture until the end of July 2006. Medical doctors (specializing in rehabilitation, exercise medicine and psychiatry), pharmacists, nurses, and kinesipathists assessed their baseline characteristics.

\section{Assessment of dietary intake}

The short version of a previously published self-administered food frequency questionnaire (FFQ) [17] was used for the present study. This included 75 food items with specified serving sizes that were described by natural portions or standard weight and volume measures of the servings commonly consumed in our study population. For each food item, participants indicated their mean frequency of consumption over the past year in terms of the specified serving size by checking 1 of the 7 frequency categories ranging from "almost never" to "2 or more times/d". Frequency data was converted to the gram intake as described previously [18]. The mean daily intake of nutrients was calculated using an ad hoc computer program developed to analyze the questionnaire. In the validity study of the present FFQ, the questionnaire provided close estimation of nutrients compared to the 3-day diet record [19].

\section{Assessment of other variables}

In addition to diet, we investigated the following factors related to fractures according to a WHO report [20]: age, gender, BMI calculated as weight $(\mathrm{kg}) /$ height $(\mathrm{m})$ squared, MMSE as a measure of cognitive function, the medical outcome study questionnaire (MOS) [21] for ADL, smoking, past falls, past history of apoplexy, diabetes mellitus, osteoporosis, renal disease and cancer. Also we investigated the use of stabilizers, hypnotics, steroids and hormone replacement therapy (HRT). Anthropometric measurements i.e. height and body weight were recorded using a standard protocol. Alcohol consumption and use of supplements including calcium and multivitamins were assessed from the FFQ.

\section{Diagnosis of fracture}

The incidence and causes of any fractures were investigated based on insurance claim records from July 2002 until July 2006. Fracture data was available on all 877 participants including 39 subjects who had died in the follow-up period. All clinical records of patients with fractures were reviewed by a physician (R.N.). Cases involving traumatic fracture such as traffic accidents were included in the "Non fall-related fracture group".

\section{Statistical analysis}

Factor analysis was used to derive dietary patterns and to determine factor loadings for each of the 27 food subgroups. Factor analysis is a statistical method used to describe variability among observed variables in terms of fewer unobserved variables called factors [22]. Factors were rotated with varimax rotation to maintain uncorrelated factors and enhance interpretability. Dietary patterns were named according to the nature of the food groups loading highest for each of the factors. For each pattern and each participant, we calculated a factor score by summing the consumption of each food item weighted by its factor loading [18]. The subjects were divided into tertiles according to the factor score as follows: unconfirmed (the first tertile: T1), moderately confirmed (the second tertile: T2) and confirmed (the third tertile: T3) according to the factor score of each dietary pattern

A simple logistical regression model was used to examine the relationships between the risk of fall-related fracture and general characteristics. Sample characteristics for T1, T2 and T3 in each dietary pattern were statistically analyzed using the parametric test. The Cox propor- 
tional hazards regression model was also used to examine the relationships between other variables mentioned above and the incidence of fall-related fractures with adjustment for age, gender [23], BMI [24] and energy intake. Hazard ratio (HR) and 95\% CIs were calculated. The probabilities of being fracture free were estimated using the Kaplan-Meier product-limit method. Fracture free numbers were calculated from the date of enrolment to the date of fracture onset, or cut-off date for participants alive at the time of closure of the dataset. A significant difference was defined as $\mathrm{p}<0.05$. All statistical analyses were performed using the Statistical Analysis System 9.1 edition for WINDOWS (SAS Institute Inc, Cary, NC)

\section{Ethics}

The Institutional Review Board of Tohoku University Graduate School of Medicine approved the protocol of the study. Written informed consent was obtained from study participants. The study was not registered to any clinical trial registration websites because the study started in 2001 and the recruitment of participants was completed in 2002.

\section{Results}

\section{Study population}

Of the 877 registered participants, 39 had suffered a fracture by the end of July 2006. Eleven participants had fractures due to traffic accident or other injuries. Therefore, we compared the remaining 28 , who fractured due to a fall, to the other 849 participants who did not have a fall related fracture within our follow up period (Figure 1). Eleven persons who had fractures due to traffic accident or other injuries were included in the non fall-related fracture group. Their background, including age, height, weight, BMI, MMSE, MOS, energy intake, gender, history of stroke, diabetes, kidney disease, osteoporosis, cancer, use of tranquilizers, sleeping pills, steroids, supplements, HRT, smoking habit or alcohol, and falls in the previous 6 months were compared between the fall-related fracture and non fall-related fracture group. There were statistically significant differences in age (a mean of 82.3 years old in the fracture group and 79.1 years old in the non fall-related fracture group, $\mathrm{p}=0.01$ ) and smoking habit (a rate of $21.4 \%$ in the fall-related fracture group and $43.7 \%$ in the non fall-related fracture group, $\mathrm{p}=0.026$ ) (Table 1 ).

\section{Dietary patterns identified}

The factor-loading matrices are shown in Table 2. Factor 1 is loaded on a high consumption of vegetables, seaweeds, mushrooms, soy products and salt. Therefore, factor 1 was designated the Vegetable pattern. Factor 2 was designated the Meat pattern because it was loaded with a

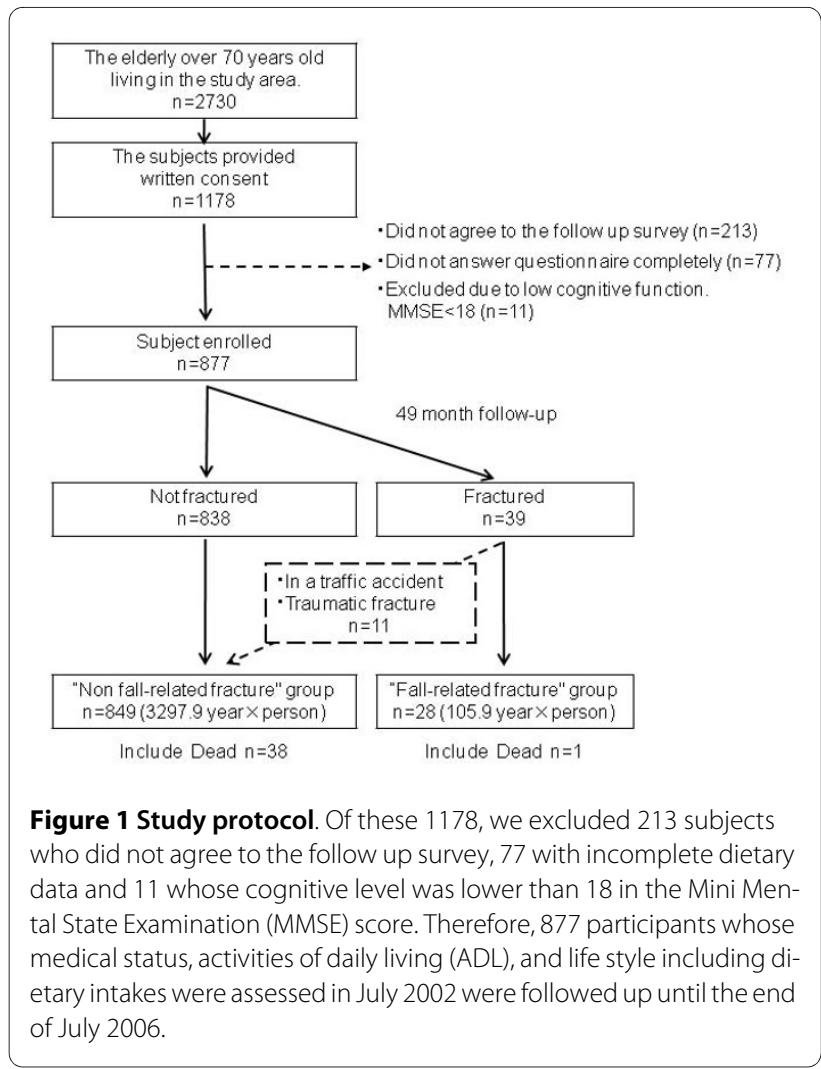

high consumption of meat (chicken, pork and beef), processed meat (ham, sausage, liver paste) and seafood (squid, octopus, shrimp, lobster and shellfish). Factor 3 was heavily loaded with rice and Miso soup intake. Also, this factor was mildly loaded with Natto (fermented soybean, a typical traditional soy product in East Asia). Therefore, we designated this factor as the Traditional Japanese pattern. The scree plots dropped on 2.5 after the third factor, factor 1 (eigenvalue 5.0) explaining 15.5\% of the variability, factor 2 (3.0) explaining 7.3\%, and factor 3 (2.8) explaining 7.2\%.

Sample characteristics for T1, T2 and T3 in each dietary pattern are displayed in Additional file 1, Table S3. ADL (MOS), past history of diabetes and use of supplements showed a significant trend in the Vegetable pattern. Age, height, weight, ADL, \% of male, past history of osteoporosis (decreased) and cancers (decreased), smoking and drinking habits showed significant trends in the Meat pattern. Finally, Height, weight, ADL (MOS), percentage of male, past history of stroke, diabetes, osteoporosis (decreased) and cancers (decreased), smoking and drinking habits showed significant trends in the Traditional Japanese pattern.

Intake of energy, total, animal and vegetable proteins, Vitamins Bs, C, D, K and electrolytes showed significant increase from $\mathrm{T} 1$ to $\mathrm{T} 3 \mathrm{in}$ all three dietary patterns. Alco- 
Table 1: General characteristics between the fracture and non fracture groups.

\begin{tabular}{|c|c|c|c|c|c|c|c|}
\hline \multirow[b]{2}{*}{ Age (years old) } & \multicolumn{3}{|c|}{ Fall-related fracture group $(n=28)$} & \multicolumn{3}{|c|}{ Non fall-related fracture group $(n=849)$} & \multirow{2}{*}{$\begin{array}{r}\text { p value } \\
0.001\end{array}$} \\
\hline & 82.3 & \pm & 5.9 & 79.1 & \pm & 4.6 & \\
\hline Height (cm) & 151.9 & \pm & 9.3 & 154.6 & \pm & 8.7 & 0.121 \\
\hline Weight (kg) & 54.2 & \pm & 9.0 & 57.0 & \pm & 9.6 & 0.121 \\
\hline $\mathrm{BMI}\left(\mathrm{kg} / \mathrm{m}^{2}\right)$ & 23.4 & \pm & 3.1 & 23.8 & \pm & 3.3 & 0.528 \\
\hline MMSE & 26.6 & \pm & 2.7 & 27.5 & \pm & 2.3 & 0.058 \\
\hline MOS score & 3.9 & \pm & 1.8 & 4.3 & \pm & 1.7 & 0.227 \\
\hline Energy intake & 2025 & \pm & 640 & 1998 & \pm & 495 & 0.782 \\
\hline Gender (male) & & $28.6 \%$ & & & $44.8 \%$ & & 0.096 \\
\hline Stroke history & & $7.1 \%$ & & & $5.3 \%$ & & 0.671 \\
\hline Diabetes history & & $17.9 \%$ & & & $13.8 \%$ & & 0.541 \\
\hline Kidney disease history & & $0.0 \%$ & & & $7.3 \%$ & & 0.997 \\
\hline Osteoporosis history & & $3.6 \%$ & & & $7.3 \%$ & & 0.462 \\
\hline Cancer history & & $21.4 \%$ & & & $12.8 \%$ & & 0.192 \\
\hline Use of stabilizer & & $10.7 \%$ & & & $13.3 \%$ & & 0.691 \\
\hline Use of hypnotic & & $7.1 \%$ & & & $10.7 \%$ & & 0.549 \\
\hline Use of steroid & & $3.6 \%$ & & & $4.0 \%$ & & 0.908 \\
\hline Use of supplement & & $10.7 \%$ & & & $18.1 \%$ & & 0.589 \\
\hline Use of HRT & & $39.3 \%$ & & & $3.7 \%$ & & 0.998 \\
\hline Smoking habit & & $21.4 \%$ & & & $43.7 \%$ & & 0.026 \\
\hline Drinking habit & & $35.7 \%$ & & & $52.1 \%$ & & 0.085 \\
\hline $\begin{array}{l}\text { Experience of falls in previous } 6 \\
\text { months }\end{array}$ & & $25.0 \%$ & & & $16.5 \%$ & & 0.252 \\
\hline
\end{tabular}

Variable are presented as mean \pm SD or $\%$.

BMI; body mass index, MMSE; Mini Mental State Examination, MOS score; medical outcome study questionnaire, HRT; Hormone Replacement Therapy.

Analysis by Simple logistic regression model

Data in bold are $\mathrm{p}<0.05$

hol intake also significantly increased from $\mathrm{T} 1$ to $\mathrm{T} 3$ in the Meat pattern and the Traditional Japanese pattern (Additional file 2, Table S4).

\section{Hazard ratio of fall related fractures}

The hazard ratios (HR) of fall-related fractures in each dietary pattern are shown in Table 3 . The vegetable pattern showed a significant trend for the risk of fall-related fracture. In this pattern, the HR of T3 (confirmed group) compared to T1 (unconfirmed group) was 2.67 (95\% CI 1.03 - 6.90) when data was adjusted for age, gender and BMI. The $\mathrm{p}$ trend in the Meat pattern for fall-related fracture risk was 0.056 when age, gender, BMI and energy intake were adjusted. The HR of T2 versus T1 in the Meat pattern was 0.36 (95\% CI 0.13 - 0.94). Figure 2 indicates the accumulated rate of fall-related fracture onset in tertiles of the Vegetable pattern. The cumulative fall-related fracture incidence in T3 (confirmed) of the Vegetable pat- tern was higher than T1 or T2. Figure 3 shows that the cumulative fracture incidence in T1 (unconfirmed) of the Meat pattern is higher than T2 or T3. Finally, there was no significant tendency towards fall-related fracture risk in the Traditional Japanese pattern.

Among the 75 food items, vegetables with light green leaves such as lettuce and cabbage $(\mathrm{HR}=0.97$ for $1 \mathrm{~g}$ intake, $95 \%$ CI $0.94-1.00, p=0.023$ ) were found to significantly reduce the risk of fall-related fracture when adjusted for age, gender, BMI and energy intake (Table 4). In contrast, seaweed $(H R=1.04,95 \%$ CI $1.00-1.08)$, root vegetables $(\mathrm{HR}=1.02,95 \% \mathrm{CI} 1.00-1.03)$, ice cream $(\mathrm{HR}$ $=1.01,95 \% \mathrm{CI} 1.00-1.01)$ and snacks $(\mathrm{HR}=1.04,95 \% \mathrm{CI}$ $1.01-1.07, \mathrm{p}=0.008)$ significantly increased the risk of fall-related fracture. The significance of seaweed and roots vegetables was removed when data was adjusted for energy intake. No other food, including dairy products, shellfish, fish, fruit, soybeans and meat showed any rela- 
Table 2: Factor analysis for patterns identified (Factor-loading matrix).

\begin{tabular}{|c|c|c|c|}
\hline & $\begin{array}{c}\text { Factor 1: } \\
\text { The Vegetable pattern }\end{array}$ & $\begin{array}{c}\text { Factor 2: } \\
\text { The Meat pattern }\end{array}$ & $\begin{array}{c}\text { Factor 3: } \\
\text { The Traditional Japanese pattern }\end{array}$ \\
\hline Radish, Turnip & 0.72 & 0.12 & 0.08 \\
\hline Carrot, Pumpkin & 0.71 & 0.01 & 0.00 \\
\hline Vegetables with light green leaves & 0.64 & 0.25 & -0.10 \\
\hline Salt intake & 0.59 & 0.16 & 0.11 \\
\hline Vegetable with green leaves & 0.56 & 0.19 & -0.06 \\
\hline Seaweed & 0.53 & 0.15 & 0.04 \\
\hline Potato & 0.52 & 0.00 & 0.22 \\
\hline Mushroom & 0.51 & 0.17 & -0.12 \\
\hline Soy product & 0.51 & 0.03 & 0.34 \\
\hline Tomato & 0.49 & 0.01 & -0.03 \\
\hline Fish & 0.36 & 0.26 & 0.05 \\
\hline Egg & 0.21 & 0.20 & 0.13 \\
\hline Pork, beef, ham, liver & 0.08 & 0.68 & 0.09 \\
\hline Chicken & 0.04 & 0.61 & 0.19 \\
\hline Shellfish, Cuttlefish, Octopus, Shrimp & 0.13 & 0.53 & -0.05 \\
\hline Noodle & 0.22 & 0.43 & -0.12 \\
\hline Coffee & 0.11 & 0.33 & -0.01 \\
\hline Coke & -0.09 & 0.31 & 0.12 \\
\hline Milk & 0.22 & -0.25 & 0.15 \\
\hline Pickled vegetable & 0.22 & 0.24 & 0.09 \\
\hline Black tea, Oolong tea & 0.08 & 0.14 & -0.08 \\
\hline Miso soup & 0.17 & 0.07 & 0.72 \\
\hline Rice & -0.04 & 0.12 & 0.69 \\
\hline Natto (fermented soybeans) & 0.37 & -0.05 & 0.43 \\
\hline Persimmon, Strawberry, Kiwi & 0.29 & -0.01 & -0.41 \\
\hline Citrus & 0.35 & -0.07 & -0.39 \\
\hline Green tea & 0.13 & -0.03 & 0.31 \\
\hline Percentage of variance (\%) & $15.5 \%$ & $7.3 \%$ & $7.2 \%$ \\
\hline
\end{tabular}

Data for 877 subjects from the FFQ

Data highlighted in bold

tion to the risk of fall-related fracture ( $\mathrm{p}$ values were over $0.05)$.

\section{Discussion}

The present study is a population based prospective study investigating the relationship between dietary patterns and fall-related fractures in elderly Japanese. Three dietary patterns that appeared in our study are similar to the study of Shimazu et al. who studied Japanese middle age to old age (from 40 to 79) [25]. The Vegetable pattern showed a significant trend for the risk of fall-related frac- ture. The T3 (confirmed group) showed a significant increase in fall-related fracture risk compared to $\mathrm{T} 1$ (unconfirmed group) in the Vegetable pattern. In analysis of each food item, vegetables with light green leaves reduced the fall related fracture risk whereas root vegetables and seaweeds increased the risk. Therefore, not all vegetables increases the risk of fall-related fracture, though the Vegetable pattern showed a significant risk increase overall.

In contrast, T2 (moderately confirmed group) in the Meat pattern showed a significant decrease in fall-related 
Table 3: Hazard ratio $(95 \% \mathrm{Cl})$ of fall-related fracture in each dietary pattern.

(3403.8 year*person)

\begin{tabular}{|c|c|c|c|c|}
\hline & $\begin{array}{c}\text { T1 } \\
\text { (unconfirmed) }\end{array}$ & $\begin{array}{c}\mathrm{T} 2 \\
\text { (moderately confirmed) }\end{array}$ & $\begin{array}{c}\text { T3 } \\
\text { (confirmed) }\end{array}$ & $\begin{array}{c}p \\
\text { for trend }\end{array}$ \\
\hline \multicolumn{5}{|l|}{ The Vegetable pattern } \\
\hline Model 1 Hazard Ratio & 1.00 (Reference) & $1.13(0.38-3.36)$ & $2.67(1.03-6.90)$ & 0.025 \\
\hline Model 2 Hazard Ratio & 1.00 (Reference) & $1.11(0.37-3.31)$ & $2.66(1.03-6.87)$ & 0.025 \\
\hline Model 3 Hazard Ratio & 1.00 (Reference) & $1.12(0.37-3.39)$ & $2.64(0.93-7.47)$ & 0.044 \\
\hline Model 4 Hazard Ratio & 1.00 (Reference) & $1.10(0.36-3.34)$ & $2.62(0.93-7.41)$ & 0.044 \\
\hline \multicolumn{5}{|l|}{ The Meat pattern } \\
\hline Model 1 Hazard Ratio & 1.00 (Reference) & $0.43(0.17-1.10)$ & $0.58(0.23-1.47)$ & 0.211 \\
\hline Model 2 Hazard Ratio & 1.00 (Reference) & $0.43(0.17-1.12)$ & $0.58(0.23-1.47)$ & 0.212 \\
\hline Model 3 Hazard Ratio & 1.00 (Reference) & $0.36(0.13-0.94)$ & $0.36(0.12-1.06)$ & 0.056 \\
\hline Model 4 Hazard Ratio & 1.00 (Reference) & $0.36(0.14-0.96)$ & $0.36(0.12-1.06)$ & 0.057 \\
\hline \multicolumn{5}{|c|}{ The Traditional Japanese pattern } \\
\hline Model 1 Hazard Ratio & 1.00 (Reference) & $0.79(0.33-1.91)$ & $0.80(0.28-2.28)$ & 0.646 \\
\hline Model 2 Hazard Ratio & 1.00 (Reference) & $0.81(0.33-1.96)$ & $0.81(0.29-2.30)$ & 0.661 \\
\hline Model 3 Hazard Ratio & 1.00 (Reference) & $0.75(0.31-1.81)$ & $0.75(0.26-2.17)$ & 0.561 \\
\hline Model 4 Hazard Ratio & 1.00 (Reference) & $0.77(0.32-1.86)$ & $0.76(0.26-2.19)$ & 0.579 \\
\hline
\end{tabular}

Analysis by Cox proportional hazards model

Model 1: Adjusted by age, gender and BMI

Model 2: Adjusted by Model 1 variable and experience of falls in previous 6 month

Model 3: Adjusted by age, gender, BMI and Energy intake

Model 4: Adjusted by Model 3 variable and experience of falls in previous 6 month

Data in bold are $\mathbf{p}<\mathbf{0 . 0 5}$

fracture risk compared to T1 (unconfirmed group). The trend shown in the meat pattern can be interpreted as $\mathrm{T} 1$ group has a tendency to increased risk of fall-related fracture relative to T2 or T3 (see Figure 3).

Our results in dietary pattern analysis appear to contradict previous reports investigating the relationship between dietary patterns and BMD. Tucker et al. [13] reported that a dietary pattern with a high consumption of fruit, vegetables and cereals resulted in greater BMD, while Okubo et al. [14] showed that a Western pattern with a high intake of fat, meat, butter and seasonings was negatively associated with BMD. Single food item analysis in our study also showed that the variety of vegetables reduces the risk of fall related fracture. Only Xu et al. [26] reported that a high intake of meat at a young age reduced the risk of forearm fracture in postmenopausal women. No other researcher has indicated a relationship between the intake of meat and bone health.

Discrepancies between the present and previous studies may be partially explained by differences in population characteristics. All participants in our study were Japanese older than 70 years. The mean meat intake in
Japan was only $77.5 \mathrm{~g} /$ day in 2002 [27] whereas it reached $242 \mathrm{~g} /$ day in the USA in 2000 [28]. Our results should be interpreted as data from a population with low meat consumption. Some nutrients such as proteins and Vitamin Bs contained in meats are known as protective factors for fracture. Figure 2 suggests that the cumulative fall-related fracture incidence in T3 (confirmed) of the Vegetable pattern was higher than T1 or T2. In addition, Figure 3 suggests that the cumulative fracture incidence in $\mathrm{T} 1$ (unconfirmed) of the Meat pattern is higher than T2 or T3. In other words, excessive reliance on low meat or high vegetable intake may cause nutritional imbalances and increase the fracture risk in such a population. Nutritional analysis showed an increasing intake of energy, proteins, Vitamin Bs, C, D, K, electrolytes, folic acid and salt from T1 (unconfirmed) to T3 (confirmed) in any dietary pattern. Therefore, all these nutritional factors, not particular ones, may synergistically contribute to the difference of fracture risk among the three dietary patterns.

Dietary patterns should be interpreted in light of regional background. Japanese food culture has been 


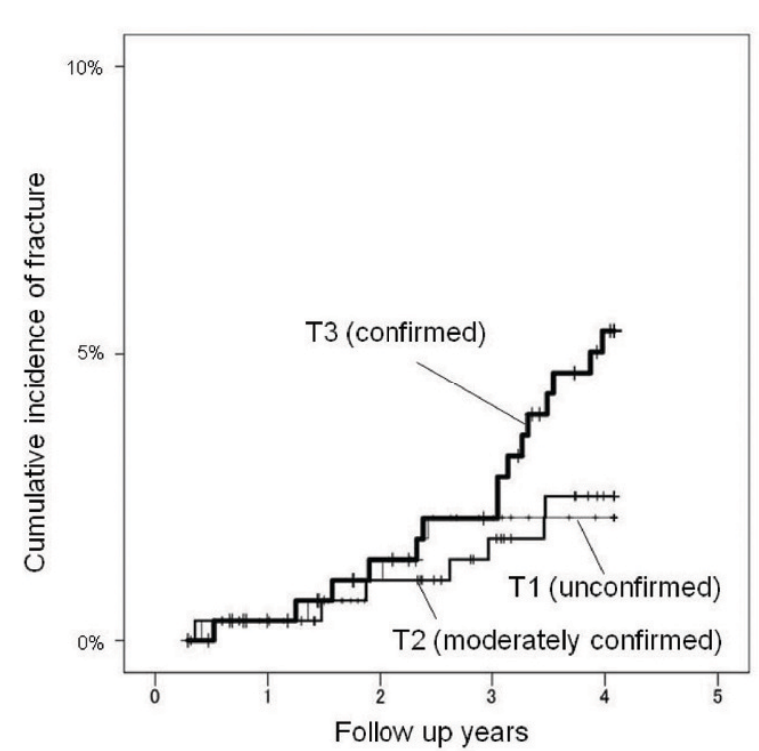

Figure 2 The accumulated rate of fall-related fracture onset in each tertile of the Vegetable pattern. The cumulative fall-related fracture incidence in T3 (confirmed) group of the Vegetable pattern is visibly higher than $\mathrm{T} 1$ or $\mathrm{T} 2$.

affected by surrounding Asian countries over many years. Interestingly, the greatest naturalist in Chinese history Li Zizhen (1518 to $1593 \mathrm{AD}$ ), reported that animal meat such as beef, ram and quail would strengthen bone and muscles in his famous textbook "the General Catalogue of

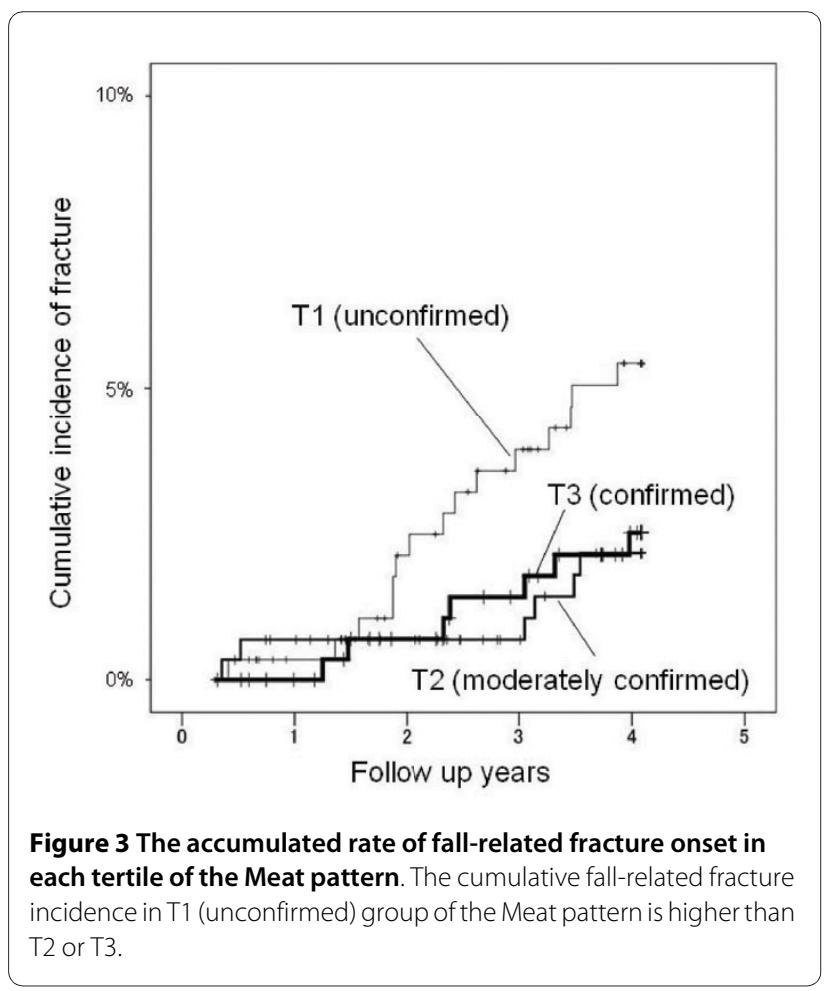

Herbs [29]". Moreover, he stated that light green leaves such as lettuce and cabbage were beneficial for bone health. Our results in a population-based prospective investigation using multivariate analysis may agree more with Li Zizhen than other recent studies.

Our study has several limitations. The number of participants included in the statistical analysis was 877 , and the number of fall-related fractures was only 28 . Therefore, we were able to adjust few factors in our analysis though many more factors are known to influence the risk of fracture. Also, the limited sample size may affect the statistical detection power. Secondly, though the study design was prospective, dietary data depended on a single cross-sectional investigation in 2002. At that time, all the participants were 70 years old or more, and they were followed for only four years. Therefore, the present study does not reflect long-term dietary habits. Diet at a young age may more strongly influence bone health $[26,30]$. However, it is very difficult to avoid biases in longitudinal investigations of lifestyle including diet over decades. The FFQ we used was validated against a 3-day diet record in women, designed to give an accurate description of short-term intake information rather than long-term dietary habits.

Though prior falls were known to lead to increasing risk of subsequent falls [31,32], we did not record the number of these falls. The Hazard Ratio of fracture, however, showed no difference after adjustment for experience of falls in the previous 6 months. Though our study was conducted on a particular cohort with certain characteristics (people living in a specific region with official health-care insurance), almost all subjects in Japan use the official medical insurance service we consulted. Therefore, our population is representative of the elderly throughout Japan. This is different to other countries i.e. USA. Finally, age at menopause is known to influence BMD [33] but it was not investigated in the present study.

Despite these limitations, the present study suggests that the impact of dietary patterns in the elderly should not be neglected when assessing the risk of fracture. In a population with low meat consumption, such as elderly Japanese, the moderate consumption of meats may reduce the risk of fall-related fracture. In discussions of diet and health, regional dietary habits should be taken into account.

\section{Conclusion}

Dietary patterns were related to the risk of fracture in elderly Japanese. The Vegetable pattern increased the risk of fracture. The Meat pattern had a tendency to reduce the risk of fall-related fracture. These results should be interpreted in light of overall low meat consumption in Japan. 
Table 4: Hazard ratio $(95 \% \mathrm{Cl})$ of fall related fracture for each food item (g/day).

(3403.8 year*person)

\begin{tabular}{|c|c|c|c|}
\hline & \multicolumn{2}{|c|}{ Hazard ratio $(95 \% \mathrm{Cl})$} & $p$ value \\
\hline Model 1 Hazard Ratio & 1.04 & $(1.00-1.08)$ & 0.031 \\
\hline Model 2 Hazard Ratio & 1.04 & $(1.00-1.08)$ & 0.032 \\
\hline Model 3 Hazard Ratio & 1.04 & $(1.00-1.08)$ & 0.054 \\
\hline Model 4 Hazard Ratio & 1.04 & $(1.00-1.08)$ & 0.056 \\
\hline \multicolumn{4}{|l|}{ Root vegetables } \\
\hline Model 1 Hazard Ratio & 1.02 & $(1.00-1.03)$ & 0.043 \\
\hline Model 2 Hazard Ratio & 1.02 & $(1.00-1.03)$ & 0.041 \\
\hline Model 3 Hazard Ratio & 1.01 & $(1.00-1.03)$ & 0.072 \\
\hline Model 4 Hazard Ratio & 1.01 & $(1.00-1.03)$ & 0.069 \\
\hline \multicolumn{4}{|c|}{ Snacks, Rice cake, Okonomiyaki } \\
\hline Model 1 Hazard Ratio & 1.04 & $(1.01-1.07)$ & 0.008 \\
\hline Model 2 Hazard Ratio & 1.04 & $(1.01-1.07)$ & 0.008 \\
\hline Model 3 Hazard Ratio & 1.04 & $(1.01-1.07)$ & 0.014 \\
\hline Model 4 Hazard Ratio & 1.04 & $(1.01-1.07)$ & 0.016 \\
\hline \multicolumn{4}{|l|}{ Ice cream } \\
\hline Model 1 Hazard Ratio & 1.01 & $(1.00-1.01)$ & 0.003 \\
\hline Model 2 Hazard Ratio & 1.01 & $(1.00-1.01)$ & 0.004 \\
\hline Model 3 Hazard Ratio & 1.01 & $(1.00-1.01)$ & 0.006 \\
\hline Model 4 Hazard Ratio & 1.01 & $(1.00-1.01)$ & 0.008 \\
\hline \multicolumn{4}{|c|}{ Vegetables with light green leaves } \\
\hline Model 1 Hazard Ratio & 0.97 & $(0.94-1.00)$ & 0.045 \\
\hline Model 2 Hazard Ratio & 0.97 & $(0.94-1.00)$ & 0.047 \\
\hline Model 3 Hazard Ratio & 0.97 & $(0.94-1.00)$ & 0.023 \\
\hline Model 4 Hazard Ratio & 0.97 & $(0.94-1.00)$ & 0.025 \\
\hline
\end{tabular}

Analysis by Cox proportional hazards model

Model 1: Adjusted by age, gender and BMI

Model 2: Adjusted by Model 1 variable and experience of falls in previous 6 month

Model 3: Adjusted by age, gender, BMI and Energy intake

Model 4: Adjusted by Model 3 variable and experience of falls in previous 6 month

Data in bold are $\mathbf{p}<\mathbf{0 . 0 5}$

Non significant foods were excluded from the table for simplicity.

\section{Additional material}

Additional file 1 Table S3: Characteristics of subjects in each tertile of identified dietary patterns

Additional file 2 Table S4: Nutrition intake of subjects in each tertile of identified dietary patterns.

Competing interests

The authors declare that they have no competing interests.

Authors' contributions

YM, KN, KI and NT were responsible for analysis and interpretation of data, and preparation of the manuscript. The first two authors, YM and KN contributed equally to the study. KN and KI were also responsible for the study concept and design. NT carried out the statistical analysis. SK, NY, HA, RN and IT were responsible for the study design. NN and $\mathrm{AH}$ are clinical investigators and they contributed to the data analysis. ST, TS and TT contributed to the preparation of the manuscript. All authors read and approved the final version of the manuscript.

Acknowledgements

We thank Ms. Kaori Ohmori-Matsuda for her data analysis support. The present study was supported by a Grant-in-Aid for Scientific Research (13557031); a Grant for Research Conducted by the Japanese Society for Promotion of Science (14010301) from the Ministry of Education, Culture, Sports, Science and Technology of Japan; research grants 2002 and 2003 from the Japanese Atherosclerosis Prevention Fund; and a Health Science Grant on Health 
Services (H16-seisaku-023) and a Grant for Comprehensive Research on Aging and health (H16-choju-016) from the Ministry of Health, Labour and Welfare of Japan

\section{Author Details}

${ }^{1}$ Graduate Medical Education Center, Tohoku University Hospital, Sendai, Japan , 2Department of Medicine and Science in Sports and Exercise, Tohoku University Graduate School of Medicine, ${ }^{3}$ Center for Asian Traditional Medicine, Tohoku University Graduate School of Medicine, ${ }^{4}$ Department of Geriatrics \& Gerontology Division of Brain Science, Institute of Development Aging and Cancer, Tohoku University, ${ }^{5}$ Department of Public Health and Forensic Medicine, Tohoku University Graduate School of Medicine and ${ }^{6}$ Department of Internal Medicine and Rehabilitation Science, Tohoku University Graduate School of Medicine

Received: 26 June 2009 Accepted: 1 June 2010 Published: 1 June 2010

\section{References}

1. Kitamura S, Hasegawa Y, Suzuki S, Sasaki R, Iwata H, Wingstrand H, Thorngren HG: Functional outcome after hip fracture in Japan. Clinical orthopedics and related research 1998, 348:29-36.

2. Giversen I. M: Time trends of mortality after first hip fractures. Osteoporosis International 2007, 18:721-731.

3. Bhattacharyya T, Chang D, Meigs JB, Estok DM, Malchau H: Mortality after periprosthetic fracture of the femur. Journal of bone and joint surgeryAmerican volume 2007, 89:2658-2662.

4. Olsson C, Petersson C, Nordquist A: Increased mortality after fracture of the surgical neck of the humerus: a case-control study of 253 patients with a 12-year follow-up. Acta Orthop Scand 2003, 74:714-717.

5. Uenishi K: Prevention of osteoporosis by foods and dietary supplements: Prevention of osteoporosis by milk and dairy products. Clinical Calcium 2006, 16:1606-1614.

6. Ikeda Y, Iki M, Morita A, Kajita E, Kagamimori S, Kagawa Y, Yoneshima H: Intake of fermented soybeans, Natto, Is associated with reduced bone loss in postmenopausal women: Japanese Population-Based Osteoporosis Study (JPOS). The journal of nutrition 2006, 136:1323-1328.

7. Eva LO, Jens EBJ, Kenneth DRS, Trine HJ: Soy milk or progesterone for prevention of bone loss: A 2 year randomized, placebo-controlled trial. Eur J Nutr 2004, 43:246-257.

8. Ho SC, Chen YM, Woo JL, Lam SS: High habitual calcium intake attenuates bone loss in early postmenopausal Chinese women: an 18month follow-up study. J Clin Endocrinol Metab 2004, 89:2166-2170.

9. Shea B, Wells G, Cranney A, Zytaruk N, Robinson V, Griffith L, Ortiz Z, Peterson J, Adachi J, Tugwell P, Guyatt G, Osteoporosis methodology group and the osteoporosis research advisory group: Meta-analyses of therapies for postmenopausal osteoporosis. VII. Meta-analysis of calcium supplementation for the prevention of postmenopausal osteoporosis. Endocrine Reviews 2002, 23:552-559.

10. Papadimitropoulos E, Wells G, Shea B, Gillespie W, Weaver B, Zytaruk N, Cranney A, Adachi J, Tugwell P, Josse R, Greenwood C, Guyatt G, The osteoporosis methodology group and the osteoporosis research advisory group: Meta-Analysis of the efficacy of vitamin D treatment in preventing Osteoporosis in postmenopausal Women. Endocrine Reviews 2002, 23:560-569.

11. Bonjour JP, Guéguen L, Palacios C, Shearer MJ, Weaver CM: Minerals and vitamins in bone health: the potential value of dietary enhancement. British journal of nutrition 2009, 101:1-16.

12. Jeri WN: Osteoporosis: the role of micronutrients. Am j clin nutr 2005 81(suppl):1232-1239.

13. Tucker KL, Chen H, Hannan MT, Cupples LA, Wilson PW, Felson D, Kiel Dp: Bone mineral density and dietary patterns in older adults: the Framingham Osteoporosis Study. Am J Clin Nutr 2002, 76:245-252.

14. Okubo H, Sasaki S, Horiguchi H, Oguma E, Miyamoto K, Hosoi Y, Kim MK, Kayama F: Dietary patterns associated with bone mineral density in premenopausal Japanese farmwomen. Am J Clin Nutr 2006, 83:1185-1192.

15. Takata Y, Maskarinec G, Franke A, Nagata C, Shimizu H: A comparison of dietary habits among women in Japan and Hawaii. Public Health Nutr 2004, 7:319-326
16. Folstein MF, Folstein SE, McHugh PR: "Mini-mental state": a practical method for grading the cognitive state of patients for the clinician. $J$ Psychiatr Res 1975, 12:189-198.

17. Sasaki S: Development and evaluation of dietary assessment methods using biomarkers and diet history questionnaires for individuals. Research for evaluation methods of nutrition and dietary lifestyle programs held on Healthy Japan 21 (head investigator: Tanaka H). In Summary report Ministry of Health, Labour and Welfare. Japan; 2004:10-44 (in Japanese)

18. Science and Technology Agency: Standard Table of food composition in Japan. In 5th revised Tokyo, Japan: Printing Bureau, Ministry of Finance; 2000. (in Japanese)

19. Sasaki S, Yanagibori R, Amano K: Self-administrated diet history questionnaire developed for health education: A relative validation of the test-version by comparison with 3-day diet record in women. Epidemiol 1998, 8:203-215.

20. WHO Scientific Group on Prevention and Management of Osteoporosis: Prevention and Management of Osteoporosis. Technical report series/ World Health Organization; 921. Geneva, Switzerland; 2003:38-46.

21. Stewart AL, Hays RD, Ware JE Jr: The MOS short-form general health survey. Reliability and validity in a patient population. Med Care 1988 26:724-735

22. Kim J, Mueller C: Factor analysis: Statistical methods and practical issues. Beverly Hills, Calif: Sage Publications; 1978.

23. Kanis JA, Johnell O, De Laet C, Jonsson B, Oden A, Oglesby A: International variations in hip fracture probabilities: implications for risk assessment. Journal of Bone \& Mineral Research 2002, 17:1237-1244

24. De Laet C, Kanis JA, Odén A, Johanson H, Johnell O, Delmas P, Eisman JA Kroger H, Fujiwara S, Garnero P, McCloskey EV, Mellstrom D, Melton LJ, Meunier PJ, Pols HA, Reeve J, Silman A, Tenenhouse A: Body mass index as a predictor of fracture risk: a meta-analysis. Osteoporos Int 2005 16:1330-1338.

25. Shimazu T, Kuriyama S, Hozawa A, Ohmori K, Sato Y, Nakaya N, Nishino Y, Tsubono Y, Tsuji I: Dietary patterns and cardiovascular disease mortality in Japan: a prospective cohort study. Int J Epidemio/ 2007, 36:600-609.

26. Xu L, Phillips M, D'Este C, Dibley M, Porteous J, Attia J: Diet, activity, and other lifestyle risk factors for forearm fracture in postmenopausal women in China: a case-control study. Menopause 2006, 13:102-110.

27. Society for the study of health and nutrition information: The actual state of national nutrition (The national nutrition survey in Japan, 2002. Ministy of health, Labour and Welfare, Japan). 1st edition. Tokyo, Japan; 2004:68-73. (in japanese)

28. In 2000, Americans consumed an average 57 pounds more meat than they did annually in the 1950's and a third fewer eggs [http:// www.usda.gov/factbook/tables/ch2table21.jpg]

29. Li Zizhen: The General Catalogue of herbs (Ben cao gong me). 2nd edition. China: People's medical publishing house; 2007. 1660-1661, $2622,2727,2749-2750$

30. Kalkwarf HJ, Khoury JC, Lanphear BP: Milk intake during childhood and adolescence, adult bone density, and osteoporotic fractures in US women. Am J Clin Nutr 2003, 77:257-265.

31. Leclerc BS, Bégin C, Cadieux E, Goulet L, Leduc N, Kergoat MJ, Lebel P: Risk factors for falling among community-dwelling seniors using homecare services: An extended hazards model with time-dependent covariates and multiple events. Chronic Dis Can 2008, 28:111-120.

32. Leclerc BS, Bégin C, Cadieux E, Goulet L, Allaire JF, Meloche J, Leduc N, Kergoat MJ: A classification and regression tree for predicting recurrent falling among community-dwelling seniors using home-care services. Can J Public Health 2009, 100:263-267.

33. Riggs $B L$, Khosla S, Melton $L J$ : A unitary model for involutional osteoporosis: estrogen deficiency causes both type I and type II osteoporosis in postmenopausal women and contributes to bone loss in aging men. J Bone Miner Res 1998, 13:763-773.

\section{Pre-publication history}

The pre-publication history for this paper can be accessed here: http://www.biomedcentral.com/1471-2318/10/31/prepub

\section{doi: $10.1186 / 1471-2318-10-31$}

Cite this article as: Monma et al., Dietary patterns associated with fallrelated fracture in elderly Japanese: a population based prospective study BMC Geriatrics 2010, 10:3 